\title{
FRAGMENTS D'INFANCIA I DE JOVENTUT DE CLAUDI ESTEVA FABREGAT
}

Berta AlCAÑIz Rodrícuez

El Colegio de Jalisco alcanizberta@gmail.com

Magnífic Rector Dr. Josep Anton Ferré, Consell de Govern, estimats collegues, estudiants, familiars i amics,"

En nom del meu marit els manifesto l'agraïment per aquest alt honor, la notícia del qual el va omplir d'alegria en vida, pel fet de rebre'l d'aquesta prestigiosa Universitat Rovira i Virgili, reconeguda internacionalment, i en especial, en el camp de l'antropologia. També vull expressar el seu agraïment a la directora del Departament d'Antropologia, la Dra. Mabel Gracia Arnaiz; al Dr. Juanjo Pujadas Muñoz, i molt especialment als seus padrins, el Dr. Joan Prat Carós i el Dr. Àngel Martínez Hernáez, per la generosa lloança que han fet del seu mestratge i de la seva obra. Avui rebo aquest honor en nom seu amb tota humilitat i gratitud com ho hauria fet

\footnotetext{
*Aquest text es correspon a les paraules de reconeixement pronunciades per la senyora Berta Alcañiz Rodríguez en la Investidura com a doctor honoris causa a títol pòstum del senyor Claudi Esteva Fabregat. Sessió acadèmica extraordinària del 10 de novembre de 2017.
} 
ell. Aquesta dignitat doctoral que se li concedeix a títol pòstum esdevé el colofó d'una vida entregada per complet a l'antropologia.

Claudi Esteva Fabregat va néixer a Marsella l'i1 de novembre de l'any 1918, el mateix dia de la firma de l'armistici que donava fi a la Primera Guerra Mundial.

El pare i la mare del Claudi vivien a Barcelona. La família de la seva mare era originària de Torreblanca, Castelló, i el seu pare era nascut a Sant Sebastià. Els dos tenien familiars a Marsella i compartien una gran admiració per França, on el pare havia treballat i la mare hi havia residit durant un temps. El pare i la mare parlaven català i francès. S'havien conegut a la colònia de catalans que hi havia a Marsella, però de casats van viure sempre a Barcelona. En un dels viatges a França, per veure els seus familiars, la mare estava embarassada i, sense programar-ho, casualment, el Claudi va néixer a Marsella. Passats els quaranta dies després del part, van tornar a Barcelona. De petit, el Claudi va passar molts estius a Ais de Provença, on es trobava amb els seus oncles i cosins. A ell li era més familiar Marsella que qualsevol altra ciutat d'Espanya i, en aquest sentit, la influència francesa que va rebre va ser més gran que la castellana.

Claudi Esteva Fabregat va ser fill únic. Quedà orfe de pare als onze anys. Sempre va guardar un record afectuós i emocionat d'ell, que l'havia fet sovint partícip dels seus interessos. El pare era especialista en metallúrgia d'alumini i acostumava a entretenir-lo amb petits invents i trencaclosques i resolent problemes mecànics, als quals era molt aficionat. Desitjava que el Claudi fos enginyer i el preparava perquè ho fos jugant-hi en matemàtiques i geometria. El seu pare fou un home francòfil. Li agradava llegir i tenia una petita biblioteca d'autors francesos. Llegia Víctor Hugo, Balzac i Alexandre Dumas, animava el Claudi a llegir i li explicava els llibres. Amb el pare sortien a passejar i feien llargues caminades mentre li relatava els episodis dels tres mosqueters. Aficionat al futbol, portava el seu fill a veure alguns partits de segona divisió; així es va iniciar la gran afició al futbol del Claudi, que jugà en equips infantils i juvenils. El pare guanyava un sou com a encarregat d'una fabrica, i mentre fou viu la família va viure còmodament. 
Amb la mort del pare, l'any 1930, la mare, viuda amb 29 anys, va haver de posar-se a treballar i ho va fer com a treballadora tèxtil en una fabrica que hi havia prop de casa, al barri de Sants. Treballava els dos torns per poder mantenir el fill i pagar-li l'escola. El Claudi va sentir moltíssim la mort del pare: es va tornar més tímid i reservat, i passava llargues hores sol a casa jugant i llegint. La mare s'aixecava a les cinc del matí per anar a treballar en el primer torn; quan acabava tornava a casa per donar el dinar al fill, i de seguida se'n tornava a la fabrica per treballar en el segon torn. Quan arribava a casa a la nit ja eren les onze i el seu fill sovint ja dormia.

La mare va matricular el Claudi en una acadèmia, una petita escola privada que tenia el mestre Lluís Roig a casa seva, on preparava a estudiants per presentar-se per lliure a l'examen oficial després de cada curs. El mestre va exercir una gran influència en la formació acadèmica i humana del Claudi: per a ell fou el relleu didàctic del seu pare. Es quedava a dinar a casa amb la seva família i fins i tot li va ensenyar a tocar una mica el piano. El Claudi va ser sempre un alumne brillant a l'escola. El mestre Lluís Roig parlava amb la seva mare de les qualitats que tenia el seu fill per estudiar i que valia la pena que fes l'esforç perquè continués estudiant el batxillerat, després de concloure els cursos que s'ensenyaven a l'acadèmia, per poder anar després a la universitat.

La mare es casà tres anys després de quedar viuda. El Claudi era un jove de tretze anys a qui agradava molt estudiar i llegir. Després de la mort de seu pare s'havia acostumat a estar sol, i això intensificava la seva independència. El padrastre volia disciplinar-lo fent que deixés d'estudiar i treballés per guanyar-se la vida. Pensava que era un noi rebel, que no volia treballar, i que el millor fonament de la vida era mercantilista: comprar i vendre. Li negava tota possibilitat de seguir estudiant i de poder anar a la universitat, que era el que ell volia. Per al padrastre, la universitat era un lloc de rics i ells eren de classe treballadora. Amb autoritarisme i càstigs pretenia que el Claudi treballés de venedor, intentant introduir en ell valors materialistes que no conjugaven amb la sensibilitat, estètica i amb l'espiritualitat del Claudi.

Ell, en veure que no podia continuar amb els estudis de batxillerat, va començar a treballar i a estudiar als vespres càlcul mercantil a l'acadèmia 
Calduch. Mentre estudiava va treballar d'aprenent en diferents oficis. No li agradava el treball manual, més aviat el rebutjava, i canviava de feina sovint fins que va a entrar a treballar a la llibreria Bastinos. Treballava per pagar els estudis i comprar-se els llibres, per així ajudar la seva mare. Ella li donava diners per a l'autobús, però ell preferia anar caminat a la feina, a la llibreria, que era al carrer Pelai, i gastar-los comprant el diari.

El Claudi va ser un àvid lector des de molt jove. Per influència del seu pare ja havia llegit fins aleshores a Han d'Islàndia de Víctor Hugo i Els Tres Mosqueters d'Alexandre Dumas. En els seus interessos particulars d'adolescent havia llegit el bandoler Dick Turpin i el detectiu Sexton Blake. Li agradaven molt especialment les aventures de l'oest de Bou Assegut, Buffalo Bill i algunes de Zane Grey. Junt amb la lectura, gaudia del cinema, dels musicals de Hollywood i de la seva gran afició a jugar a futbol, primer com a juvenil en l'equip del Sants, després en l'equip de futbol de la Penya de Sant Andreu Victòria i entrenant amb els jugadors dels juvenils del Futbol Club Barcelona. El seu equip preferit, però, era el Sants.

Cap als catorze anys el Claudi va començar a freqüentar l'Ateneu Enciclopèdic Sempre Avant de Sants. Utilitzava molt la biblioteca i el gimnàs. Li agradava sentir les converses i discussions que hi havia a la tarda a l'Ateneu entre joves militants anarquistes, llibertaris, comunistes i nacionalistes, la majoria empleats i treballadors, que hi anaven després de la jornada de treball. Estaven tots bastant al corrent de les notícies polítiques internacionals.

Va alternar els contactes amb les Joventuts Llibertàries, que tenien una gran influència anarcosindicalista en aquell moment, i amb el moviment nacionalista català. Amb els seus amics llibertaris del barri de Sants assistia a sessions que organitzaven les Joventuts Llibertàries on els parlaven de l'opressió del proletariat, de Bakunin, Kropotkin, Proudhon i Malatesta. Encara que el Claudi sentia un gran respecte cap als vells militants anarquistes del seu barri, mai no va exercir la militància activa en aquest moviment juvenil. Més aviat era un jove intellectual romàntic de catorze o quinze anys atret per la novella i la literatura política russa i francesa. Havia llegit Turguénev, Gógol, Dostoievski, Tolstoi i quatre o cinc escrip- 
tors francesos: Sthendal, Balzac, Malraux i André Gide, i li impressionà especialment l'obra El Foc de Barbusse.

A l'Ateneu entrà en contacte amb Antoni Cuberes, un jove que el va iniciar en la idea del nacionalisme separatista al parlar-li de Catalunya com un país oprimit, i que en conseqüència els catalans no eren lliures. El plantejament del Claudi sobre aquests temes es va capgirar. Fins aleshores la seva posició ideològica era més aviat anarquista: l'home ha de ser lliure per construir una societat lliure, i ara s'invertien els termes i havia de lluitar primer per aconseguir un país lliure que ens portés a tots la llibertat. El Claudi va quedar confós per aquest nou plantejament i durant un temps alternava l'anarquisme amb el nacionalisme. Una de les altres influències que va rebre va ser la de Casanovas, un soci de l'Ateneu militant del partit comunista de Catalunya que li explicava la realitat des d'una interpretació comunista. Aleshores va començar a llegir la revista Correspondencia Internacional, d'inspiració comunista, i valorà les seves anàlisis crítiques sobre l'imperialisme i les dictadures.

El Claudi va ser un adolescent molt rebel, possiblement per influència anarcosindicalista i per la illusió utòpica de canviar el món. Ara, se sentia més independentista que anarquista. Ho atribuïa al seu romanticisme i que somniava a ser l'alliberador de Catalunya. A Catalunya hi havia tres organitzacions independentistes: Estat Català, Nosaltres Sols i el Partit Nacionalista Català. En aquell moment, el Claudi seguia sense militar en cap partit, però s'inclinava més per Estat Català. Quan esclatà el Movimiento Nacional el 19 de juliol de 1936, el Claudi ja hi militava, s'hi havia inscrit en el mes de gener del mateix any. Però hi va militar pocs mesos, ja que es va passar al recent constituit partit de les Joventuts Socialistes Unificades de Catalunya (JSUC) perquè s'hi va sentir més identificat. Per una banda, la qüestió nacional catalana es plantejava des de l'autodeterminació i trobava més ben definits i alliberadors els objectius socials per a la classe obrera i assalariada. Amb disset anys començà la seva militància intensiva a les JSUC de Sants, on aviat va ser nomenat secretari d'agitació i propaganda, i després secretari d'organització; més tard passà a formar part del Comitè de les JSUC de Barcelona, integrat per Antoni Soriano, Felip Capdevila, Gregorio López Raimundo, Vicente Bailo Gimeno. Amb ells va defensar la causa de la República i la de Catalunya durant la Guerra Civil. 
Com a conseqüència de la derrota militar, fou un més dels centenars de milers de compatriotes que creuaren els Pirineus per la Jonquera-Le Perthus el dia 11 de febrer de 1939. A França passà cent dies internat al camp de concentració de Sant Cebrià, a la Catalunya Nord, on s'hi estaven més de cent mil homes. L'experiència fou d'una gran duresa, com la que vam patir els d'altres camps de concentració. No hi havia ni barracons, dormien al ras, amb gelades, al costat del mar, i es colgaven amb la sorra de la platja perquè no tenien mantes. Els donaven un tros de pa, una presa de xocolata i aigua de cafe. Com que les autoritats franceses els prohibiren viure lliurement com a ciutadans a França, van haver de buscar altres sortides: el Claudi i el seu amic Vicente Bailo van escriure al Comitè Britànic d'Ajuda Internacional per demanar l'asil a la Gran Bretanya. Van trobar resposta a la seva sollicitud al ser elegits per anar en el primer vaixell de refugiats espanyols a Mèxic, el Sinaia. El Claudi tenia vint anys.

Al Sinaia va gaudir d'una sensació de llibertat i repòs. Va reflexionar sobre la Guerra Civil i va començar a endinsar-se en noves temàtiques, les de Mèxic, per mitjà de butlletins que s'imprimien amb ciclostil i de xerrades sobre el país que ara els acolliria com a exiliats polítics, que se'ls oferien en el mateix vaixell. El Sinaia arribà al port de Veracruz, a Mèxic, el 13 de juny de 1939. Foren rebuts per desenes de milers de persones: moltes eren treballadores aplegades pels sindicats, totes vestides de blanc, que els acollien molt afectuosament amb víctors a ells i a favor de la República espanyola, invitant-los a sentir-se com a casa. El Claudi, com molts dels altres refugiats, pensaven que el règim franquista duraria el que durés la Segona Guerra Mundial, i seguien actuant políticament a Mèxic, on es trobaven les institucions republicanes espanyoles a l'exili.

Destinat a la Ciutat de Mèxic, les primeres experiències les va fer en grup. El Servei de Refugiats Espanyols a Mèxic (SERE) els proporcionava un refugi i els distribuïa en relació amb els llocs d'origen. Al Claudi el van destinar a un departament on hi havia sis catalans i durant uns mesos els van donar a cadascú dos pesos mexicans al dia, que els permetia subsistir mínimament. Els que tenien un ofici aviat trobaven feina i invitaven a menjar els qui encara no n'havien aconseguit. Entre tots ells s'ajudaven i anaven a l'Orfeó Català buscant qui els orientés per trobar una feina. 
L'Orfeó també era un lloc de relació social de la colònia catalana i de tertúlies polítiques. Al costat de l'Orfeó hi havia la Biblioteca Nacional, on anava el Claudi els matins que tenia lliure a llegir llibres de la historia de Mèxic i, sobretot, de la Revolució Mexicana.

Després d'un any de viure a Ciutat de Mèxic, es va traslladar a la ciutat de Puebla perquè el van contractar com a futbolista a l'equip O'Farril, juntament amb altres joves refugiats. Era l'equip de futbol de la fabrica d'encaixos dels automòbils Packard. A l'equip li van posar el nom de filòsof, per la capacitat argumentativa en la defensa que feia del seu equip davant l'àrbitre. Aquests anys de joventut els va compartir amb espanyols i mexicans formant el que a Mèxic se'n diu la palomilla d'amics, i amb el seu bon amic Josep Solé Vidal, del Partit Socialista Català (PSC), que l'invità a integrar-se en el partit que s'acabava de fundar a Mèxic per part de diferents militants discrepants amb el PSUC. Quan l'equip del O'Farril va deixar d'existir, el Claudi es va quedar sense feina i va trobar un treball en la indústria tèxtil de filats de cotó. Al cap de dos anys de treballar a la fabrica es traslladà novament a Ciutat de Mèxic per continuar amb l'activitat política que el PSC li reclamava.

A Ciutat de Mèxic es retrobà amb la seva catalanitat participant en les activitats que organitzava la colònia catalana a l'Orfeó Català. Seguí treballant en el ram de la indústria tèxtil, visitant fabriques i oferint peces pels telers. Les facilitats que oferia el govern mexicà va fer que prengués en ferm la decisió, fins aleshores frustrada, d'estudiar una carrera universitària. D'una forma casual conegué l'Escuela Nacional de Antropología e Historia (ENAH). El programa de les assignatures li agradà molt i es decidí per estudiar Antropologia. Abans d'aquesta troballa no sabia que existís aquesta disciplina acadèmica. Li interessava la política i les bases filosòfiques amb les quals es podia construir una identitat. Totes dues formaven part del solatge intellectual que el Claudi havia anat adquirint $\mathrm{i}$ que ens expliquen per què ell va decidir estudiar Antropologia.

Aquests petits fragments d'infancia i joventut del Claudi Esteva Fabregat són experiències de vida d'una biografia que no ha estat estrictament acadèmica ni solament científica i que permeten definir el procés, la història personal i les condicions que el van portar a exercir plenament l'antropologia. 
Per acabar, reitero el meu agraïment profund al Magnífic Rector per aquest alt honor que a títol pòstum recullo en nom del meu marit, així com als directors i representats de l'antropologia de les universitats catalanes, representants d'institucions i collegues d'aquí i de fora, i els qui en la distància m'han fet arribar la seva adhesió.

A tots els aquí presents, gràcies per compartir aquesta solemníssima sessió i manifestar amb la vostra presència l'estima al mestre, al collega, al familiar i a l'amic. Moltes gràcies. 